\title{
Changes in School Mathematics: Curricular Changes, Instructional Changes and Indicators of Change
}

Thomas Romberg

Follow this and additional works at: https://repository.upenn.edu/cpre_researchreports

Part of the Education Commons

\section{Recommended Citation}

Romberg, Thomas. (2017). Changes in School Mathematics: Curricular Changes, Instructional Changes and Indicators of Change. CPRE Research Reports.

Retrieved from https://repository.upenn.edu/cpre_researchreports/105 
Changes in School Mathematics: Curricular Changes, Instructional Changes and Indicators of Change

\author{
Abstract \\ Discusses how the mathematics curriculum should be changed to reflect changes in the nation's \\ economic and social culture brought on by new technology. The report also outlines the National Council \\ of Teachers of Mathematics (NCTM) proposal for new curriculum and evaluation standards \\ Disciplines \\ Education
}




\section{Changes in School Mathematics Curricular Changes, Instructional Changes, and Indicators of Changes}

Thomas A. Romberg

September 1988

im

RUTGERS

Michigan State University

STANFORD UNIVERSITY

UNIVERSITY of WISCONSINMADISON 


\section{CONTENTS}

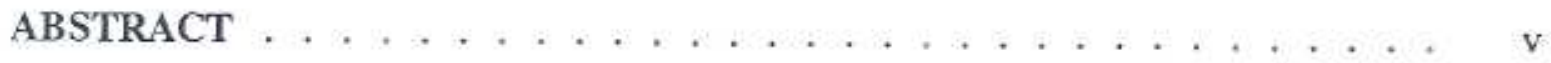

ACKNOWLEDGEMENTS ....................... vii

$\underline{\text { Section }}$

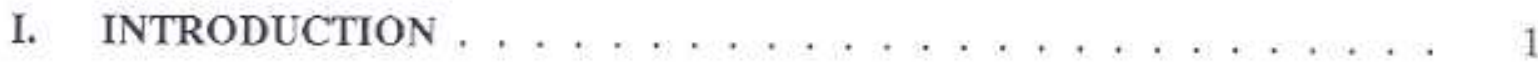

II. DEMANDS FOR CHANGE ................. . . 3

Dual Educational System . . . . . . . . . . . . . . . 3

Evidence for Needed Change . . . . . . . . . . . . . . . . 4

Response to Demands for Change .............. 7

III. NATURE OF PROPOSED CHANGES . . . . . . . . . . . . . . 11

Mathematical Literacy . . . . . . . . . . . . . 12

Perspective 1: Empirical Concepts and Procedures . . . . . . 12

Perspective 2: Abstract Concepts and Procedures ........ 13

Perspective 3: Reasoning .............. 16

Perspective 4: Applications of Mathematics . . . . . 17

The NCTM Curriculum Standards . . . . . . . . . . . . . . . . 18

Goals and Assumptions . . . . . . . . . . . . . . . . . . . . 18

Mathematical Content . . . . . . . . . . . . . . . 18

Methods of Instruction. . . . . . . . . . . . . 21

IV. APPROPRIATE INDICATORS . . . . . . . . . . . . 25

Standardized Tests . . . . . . . . . . . . . . . . . 25

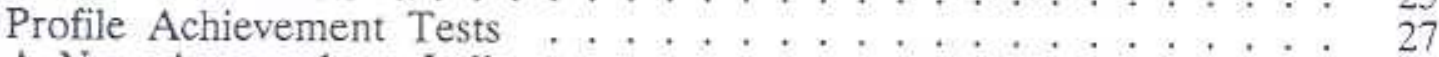

A New Approach to Indicators . . . . . . . . . . . . 30

V. IMPLEMENTATION OF CHANGES . . . . . . . . . . . . . 35

Coherence of the Educational System . . . . . . . . . . . . . 35

The "Zero-sum" Consequence of Change . . . . . . . . 36

The "Modern Math" Legacy . . . . . . . . . . . . . . . . . 37

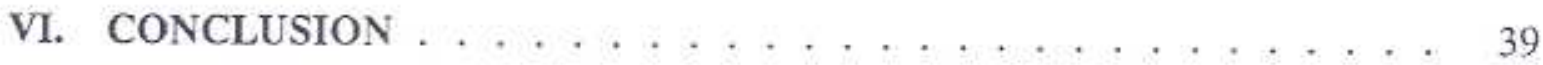

REFERENCES . . . . . . . . . . . . . . . . . . . 41 


\begin{abstract}
This paper addresses the demands for change in the teaching and learning of mathematics in the schools of America. Many of the demands stem from the way rapid changes in information technology have altered our economic and social culture. In particular, these technological changes have changed both mathematics and its applications.

Given these circumstances, this report outlines the National Council of Teachers of Mathematics proposal, Curriculum and Evaluation Standards (1987). Also discussed are the implications for instruction of the adoption of a curriculum based on these Standards. Next, the problem of developing appropriate indicators to determine the effectiveness of a school mathematics program based on these curricular and instructional changes is presented, and a domain knowledge strategy proposed. Finally, the problems of implementing these changes in the schools are identified.
\end{abstract}

While not easy to accomplish, a professional development strategy is described which, if followed, has promise in bringing about the reforms in the teaching and learning of mathematics which are being proposed. 


\section{ACKNOWLEDGEMENTS}

The preparation of this paper was greatly helped by Dr. John Dossey, pastpresident of the National Council of Teachers of Mathematics.

Thomas A. Romberg is professor of curriculum and instruction and director of the National Center for Research in Mathematical Sciences Education at the University of Wisconsin-Madison. His research has focused on two areas: young childrens' learning of initial mathematical concepts (best reflected in the JRME monograph "Learning to Add and Subtract") and methods of evaluating both students and programs (best reflected in the book Toward Effective Schooling: The IGE Experience). An article (with Tom Carpenter) that illustrates Romberg's commitment to integrating research on teaching, curriculum, and student thinking, "Research on Teaching and Learning Mathematics: Two Disciplines of Scientific Inquiry," was selected in 1988 by the American Educational Research Association as the previous year's best review of research. 


\section{INTRODUCTION}

Today educational policymakers at all levels--school, district, state and federal--are faced with a difficult dilemma with respect to school mathematics. On one hand, they are being bombarded with reports and rhetoric about the failings of current school mathematics and the need for change. Add to that clamor the responses of the mathematical sciences community to those demands for change, and it is not surprising that those responsible for educational planning and policy feel that they must make curricular and instructional changes.

On the other hand, taxpayers concerned about the growing costs of education are wary of radical educational changes for they know that any change is likely to increase costs. In addition, they are demanding more accountability. In particular, when changes are made, administrators are asked to demonstrate the effects of particular improvements. Unfortunately, the dilemma they face is that the indicators that have typically been used to estimate effects of change are unlikely to be sensitive to the changes now being proposed. Therefore, educators are being expected to change current practice in school mathematics and to document the effects of those changes with inadequate, invalid indicators.

This paper addresses four aspects of the changes in school mathematics. First, the demands for change are clarified. Second, the nature of the proposed changes in both the curriculum and instruction methods for school mathematics is described. Third, ways of developing new, and more powerful indicators for quality mathematics education are discussed in light of the other suggested changes. Finally, the problem of implementing the changes that have been described is addressed. 


\section{DEMANDS FOR CHANGE}

Since the turn of the century, critics have called for change in the school mathematics curriculum (Stanic, 1984). The primary targets for these calls for change have been at two levels. The first is the boring, menial common arithmetic curriculum of the elementary schools, and the second, the appropriateness of the secondary mathematics curriculum for further work in the discipline at a university. Thus there are concerns with both parts of the dual educational system that evolved in the U.S. in the 19th century.

\section{DUAL EDUCATIONAL SYSTEM}

In the industrial society of the past century, people were educated to maintain their places in the structure of the economy. A small highly educated group established policy, led the government, managed industry and advanced the scientific and technological base. The remainder of the population provided the physical labor for production and services and was educated to the level required for reliable performance. The result was a dual school system of "high-literacy" and "low-literacy" schools (Resnick \& Resnick, 1977). The high-literacy schools were, and still are, for the elite. Only a small percentage of young people apply, or are admitted, to such schools. The curriculum in such schools is strictly academic, aiming toward students' admission to the "best" universities in the country.

Schools for the masses arose from different roots and were aimed at producing minimal levels of competence in the general population. Early in the 1800 s, village schools were established reflecting Jeffersonian notions about a literate citizenship appropriate to the new nation. The educational system that evolved during the 19th century focused largely on the common elementary school. This produced a sharp distinction between elementary and secondary education that still persists. Almost everyone went to school for up to eight years, but few went on to high school. The low-literacy curriculum focused on the basic skills of reading, writing, and computation. In fact, the backbone of the mathematics curriculum was "shopkeeper" arithmetic. Teachers in elementary schools were expected to teach all students all the curriculum, while secondary teachers were subject-matter specialists. The political conditions under which mass education 
developed encouraged the routinization of basic skills and the standardization of teaching. Standardization was a means of insuring that at least minimal curriculum standards would be met, that teachers would be hired on the basis of competency for the job rather than political or familial affiliation, and that those responsible for the expenditure of public funds could exercise orderly oversight over the process of education. This standardization was also a consequence of the notions about the efficiency and effectiveness of routinization which grew out of the industrial revolution of the 19th century (Bobbitt, 1924; Charters, 1923; Rice, 1913).

At the other extreme, the elite have had a tradition of scholarly, cultural, and scientific high literacy; they have been prepared for academe and policymaking. Although not all were educated to the level of advanced academic study, all were rigorously educated, to allow for that option. The concerns about the elite mathematics curriculum dealt with whether the content of the secondary curriculum was up-to-date and appropriate. ${ }^{1}$

This dual educational system undoubtedly served the Industrial Age of the 19 th early 20 th centuries reasonably well, but it is no longer adequate.

Unfortunately, the traditions embedded in this dual educational system have been hard to change. They include age-graded classrooms, differential schools, tracking at an early age, licensure of general teachers, competence at paper-and-pencil arithmetic, general mathematics as the terminal course for noncollege bound students, precalculus mathematics for college intending students. It is these traditions that are now under attack.

\section{EVIDENCE FOR NEEDED CHANGE}

The evidence cited by those now demanding change concerns the effect of the current mathematics content and how it is being taught. The following points are made:

1 The "modern math" curriculum changes of the 1960 s were aimed at this concern. 
1. Employers have claimed that recent graduates have insufficient knowledge for employment. Henry Pollak (1987), a noted industrial mathematician, recently summarized what industry expects of its new employees, including:

- the ability to set up problems with the appropriate operations;

- knowledge of a variety of techniques to approach and work on problems;

- understanding the underlying mathematical features of a problem;

- the ability to work with others on problems;

- the ability to see the applicability of mathematical ideas to common and complex problems;

- preparation for open problem situations, since most real problems are not well formulated; and

- belief in the utility and value of mathematics.

Notice how different this description is from that of a student working alone on sets of well-formulated exercises. While mathematics is not taught in schools solely so students can get jobs, their experiences should not be that dissimilar from the expectations of employers.

2. College and university officials have documented that 15 percent of the current enrollment in mathematics courses at public four-year colleges is for remedial courses, and another 37 percent is for precalculus courses (Albers, Anderson, \& Loftsgaarden, 1987). There are two probable reasons for this situation. First, a mismatch exists between what is studied in school mathematics and what is needed in some college majors. Second, there has been a change in college expectations; that is, more majors now require mathematics. Many high school counselors and curriculum directors have failed to recognize this fact.

3. The bleak national performance data cannot be ignored. For example, results from the National Assessment of Educational Progress (NAEP) in mathematics (Carpenter et al., 1987) clearly show that although most students are reasonably proficient in computational skills the majority do not understand many basic concepts and are unable to apply the skills they have learned in even simple problem-solving situations.

4. When compared with students in other industrialized nations, particularly those in the Orient, our students do not fare well (McKnight et al., 1987). We expect less of our students; they spend less time studying mathematics; and fewer are enrolled in advanced mathematics than are students in other countries. 
Furthermore, such comparisons reveal other differences. Teachers abroad are full-time employees; they are paid salaries equivalent to those for engineers; they are expected to teach fewer classes; they have more help, more time to reflect and interact with others, and time to update and refresh their knowledge. Parents are also expected to help their students. And, if students have difficulty, lack of effort or help is assumed to be the cause; in this country poor student performance is usually attributed to lack of aptitude.

5. The performance and enrollment picture is even more bleak for women and most minorities. For example, on the average, black students complete approximately one year less of high school mathematics than their white classmates (Anick, Carpenter, \& Smith, 1981). Women and most minorities are seriously underrepresented in scientific and technological careers. Only 13 percent of the nation's scientists and engineers are women and only 2 percent are black (National Science Foundation, 1982). If our inequitable schooling practices are allowed to continue, this condition will get worse. Affluent suburban school districts already provide their students more opportunities and resources for the study of mathematics, and they are likely to be the first to react to the current crisis and recommendations. They are already spending more money than urban districts on computers and teacher inservice, thus widening further the opportunity gap between affluent suburban students and their poor, urban counterparts.

6. Another aspect of this concern is the mistaken belief that the mastery of paper-and-pencil procedural skills is necessary before one can investigate problems. In particular, a common unwarranted assumption is that proficiency in arithmetic computations is necessary before one can study algebra or geometry or investigate applied problems. Too many students are refused an opportunity to learn the mathematics that would make it possible for them to be productive members of society because they are not proficient at skills which are now done best on a calculator or computer.

7. Mathematics is a dynamic, growing, and changing discipline. Davis and Hersh (1981) argue that "there are two inexhaustible sources of new mathematical questions. One source is the development of science and technology, which make ever new demands on mathematics for assistance. The other source is mathematics itself .... each new, completed result becomes the potential starting point for several new investigations" (p. 25). They claim that we are 
now in a Golden Age of mathematical production, with over half of all mathematics invented since World War II. Given this explosion of knowledge, it is impossible for any one person to know all there is to know. For school programs we must select carefully and emphasize fundamental knowledge needed for contemporary mathematics. In fact, rather than attempting to cover a large number of topics somewhat superficially, it would be preferable to examine fewer topics each in more depth.

In summary, change is necessary for several reasons but primarily because many important mathematics ideas are not reflected in current programs.

\section{RESPONSE TO DEMANDS FOR CHANGE}

The clamor for change in school mathematics was brought to a head with the publication of A Nation at Risk (National Commission on Excellence in Education, 1983) and Educating Americans for the 21st Century (National Science Board Commission on Precollege Education in Mathematics, Science, and Technology, 1983). The public's attention was forcibly drawn to the urgency of the need for change by these reports. The mathematical sciences community then responded with three publications: What is Fundamental and What is Not (Conference Board of the Mathematical Sciences, 1983a); New Goals for Mathematical Sciences Education (Conference Board of the Mathematical Sciences, 1983b); and School Mathematics: Options for the 1990s (Romberg, 1984). These documents, produced from deliberations at conferences, have started in motion the current recommendations for change.

As implied earlier, the real cause underlying the need for change is the shift from an industrial to an information society. Several authors (Naisbitt, 1982; Shane \& Tabler, 1981; Toffler, 1985; Yevennes, 1985) have described some of the attributes of the new age. It is based on a new technology that replaces the human and mechanical means of communication--the printed page, letters--with electronic means by which information can be shared almost instantly with persons anywhere. Information is the new capital and the new raw material. Communication is the new means of production. One should recognize that the impact of technology is an economic reality, not merely an intellectual abstraction. As a result, the pace of change will be accelerated by continued innovation in communications and computer technology. Also, the new technologies were applied to old industrial tasks first, but now are generating new 
processes and products. And, finally, basic communication skills are more important than ever before, necessitating a literacy-intensive society. This shift has some immediate consequences for schooling and, in particular, the teaching and learning of mathematics.

The content and structure of the curriculum should not indoctrinate students with past values, but should be derived from visions of the future (Shane \& Tabler, 1981). Students in schools today must prepare to be productive citizens in the twenty-first century. The culture in that era will of necessity be different from that of today. We must attempt to visualize some of the important features of that society if we are to adequately prepare today's children for that world.

All students should be taught to reason, to design models, to create, and to solve problems. The most important attribute of the information economy is that it represents a switch from physical energy to brain power as the driving force, and from concrete products to abstractions as the primary outcomes. Instead of training all but a few children to function smoothly in the mechanical systems of factories, all children must be taught critical thinking skills. While creative intelligence is the driving force, innovation depends on communal intellectual effort rather than resting solely on the activity of a small cadre of elite thinkers. This is quite different from the concept of an intellectual elite having the responsibility for innovation while workers take care of production.

With rapid economic change, people must anticipate multicareer lives in which they may experience structural unemployment, requiring re-education. People will need a combination of education and training, education for adaptability and continued learning and on-the-job training for specific tasks.

The plethora of reports on illiteracy, dropout rates, falling test scores, and economic declines have cast a spotlight on schools and, in particular, on the failings of school mathematics. The shift from the Industrial Age to the Information Age implies a needed shift in metaphors from an industrial metaphor underlying the traditional school to an information/communication metaphor.

The industrial metaphor viewed schooling as an assembly line; students were the raw material input to the system; teachers were workers passing on a fixed body of mathematical knowledge by telling students what they must remember and do (mostly be proficient at carrying out algorithms); and the output of the system was judged by scores from tests. This metaphor was based on the need to efficiently prepare the majority of students to fit smoothly into a mass-production 
economy. To meet this need, knowledge was seen as objective, teaching as transmission and control, and learning as absorption.

Each of these assumptions has changed. Today our society needs individuals who can continue to learn and adapt to changing circumstances and produce new knowledge. Knowledge is seen as constructive, teaching as guiding, and learning as occurring through active participation. 


\section{NATURE OF PROPOSED CHANGES}

The response to the demands for reform has occured in two identifiable stages. These stages consisted of the initial response of policymakers to call for quick changes and the slower and more deliberate response from the mathematics education community as consensus on change was achieved.

In the first stage, many policymakers and educators eager to reform school mathematics made nonreflective responses to the demands for reform. For example, the majority of state legislatures mandated that mathematics requirements for high school graduation be increased and that competency tests be used for student promotion. Similarly, new syllabi have been or are being developed by school districts and state departments of education. Publishers are producing kits of manipulatives and software and are including more challenging problems in their texts. In addition, a number of experimental development projects and several research studies have been funded by the federal government and private foundations.

Unfortunately, these initial responses focused on making instruction on current content more efficient. For example, many administrators are pressing for improved performance of students on standard measures of mathematical achievement. Calls for state competency exams, teacher tests on content knowledge, a new NAEP, and national indicators all are being considered. However, most have failed to consider anything except expectations about student outcomes consistent with the industrial age, not the information age. This response has focused on strengthening current practices using standardized tests to meet accountability demands. Such practices are likely to perpetuate an outdated mathematics curriculum in a manner such as that described in the classic satire The Saber-Tooth Curriculum (Pediwell, 1939). If changes are not made, we will still be training shopkeepers who can only perform some procedural tasks that are now done by calculators and computers everywhere in society except in schools. And we justify such training on the belief that knowledge of such skills is a necessary prerequisite to the study and use of mathematics, a belief that is not supported by research (Resnick, 1987).

In reality, the traditions and assumptions that underlie the current picture of mathematics instruction are the target of the current calls for reform. Too often 
in mathematics classrooms there is no sense of exploration, curiosity, or excitement. Students see mathematics as a vast collection of vaguely related concepts and skills which are to be mastered in a strict order, and their only objective is to become competent at carrying out some algorithmic procedure in order to get correct answers on sets of stereotyped exercises. Furthermore, only the product of their work is evaluated, not how they thought about the tasks or how they proceeded. This fragmentation, emphasis on paper-and-pencil procedural skills, and form of evaluation has effectively separated students from mathematical reality, inquiry, and intellectual growth. In fact, when knowledge is fragmented, it is difficult to remember and is difficult to regenerate if forgotten.

At the second stage of reaction to the pressures for reform mathematics educators have proposed a more considered response, which I have labeled "mathematical literacy," that challenges the traditions of current mathematics instruction.

\section{MATHEMATICAL LITERACY}

The term mathematical literacy has been chosen deliberately to characterize the shift in metaphors. Kirsch and Jungeblut (1986), in their report of the NAEP study of literacy, defined literacy as using "information to function in society" (p. 3). This definition implies an ability to do something, as opposed to a knowledge of something. As Venezky, Kaestle, and Sum (1987) have stated, "Literacy . . . is a functional skill in that it requires the application of various skills in common, everyday situations" (p. 5). They pointed out that "literacy is also a continuum of skills, not an all-or-none ability" (p. 5). Thus, the development of literacy involves learning how to communicate by learning the terms, signs, symbols, and rules for use of a language and simultaneously learning to read and write messages in that language to communicate with others. Furthermore, the origins and development of literacy are situation dependent. Translating this notion of literacy to mathematics can be done by considering four perspectives.

\section{Perspective I: Empirical Concepts and Procedures}

Mathematical knowledge arises from rudimentary ideas acquired through perception of situations in the complex world around us. Several millennia ago, our ancestors planted the seed for the enterprise by observing some quantitative 
and spatial regularities. From these humble beginnings, mathematics has flowered into the impressive body of knowledge that we have been fortunate enough to inherit. Thus, from its origins, mathematics was an empirical science. Its fundamental terms, signs, symbols, and rules are merely abstractions and inventions created to represent properties observed in the environment. Numbers were created to represent the numerousity of sets of familiar objects; signs such as " + " were invented to represent the quantity found by the joining of sets; and terms such as parallel and perpendicular were introduced to name spatial properties. The purpose of creating a language is to communicate with others. The terms of the language only become useful when there are shared meanings for them. Thus, mathematics is both a language that man has created and a set of rules for the use of that language. Its origins are to be found in the regularities of the world in which we live. Like any language, mathematics grows and changes as a result of empirical investigations. To be literate, all students need to confront a rich array of the common problem situations from which they can gradually build the empirical language of mathematics, its notation, and its rules so that they share a common meaning for its terms.

\section{Perspective 2: Abstract Concepts and Procedures}

A good deal of mathematical knowledge has been created by making the empirically based language and set of rules the objects of man's investigation. Again, by observing properties of numbers, operations, and spatial figures, for example, humans, by abstraction and invention, have created another set of terms, signs, symbols, and rules. Some are generalizations of empirical procedures. For example, the creation of computational algorithms for empirical processes has made mathematics applicable to many seemingly unrelated problem situations. In addition, being no longer bound by perceptual reality, man has extended mathematics by asking "What if ... ?" questions. For example, while the creation of an equation for the shortest distance between two points on a plane surface has empirical origins, the generalization of this formula to two points in n-dimensions does not. And, while multiplication of whole numbers has its roots in the grouping of objects empirically, more abstract multiplication algorithms do not. They grew out of observations about properties of exponents such as $\underline{a}^{\mathrm{X}}$. $\underline{a}^{\mathrm{y}}$ $=\underline{a}^{x+y}$ and the fact that any decimal number can be expressed as an exponent through use of powers of ten. Thus, mathematics involves the study of abstract 
systems that grow as a result of investigating different problem situations. Hence, to be mathematically literate, all students need the opportunity to explore the properties of the empirically derived mathematics and to come to see for themselves the relationships, rules of transformations, extensions, and structures derived from these investigations.

The descriptions of the "content to be learned" for both the empirical and the abstract languages of mathematics should be conceived as semantic networks or domains. Each domain consists of a set of signs, symbols, rules, and problem situations that are closely related. The problem situations are those that historically have given meaning to signs and symbols being learned--empirical situations for some and abstract for the others. Because these domains have a common interrelated set of ideas, we have often given the domains labels, such as whole numbers and coordinate geometry. Thus, the content of school mathematics should be identified by use of these common labels; however, in each case, the referent is the domain or network of ideas that is being identified. For example, the related mathematical concepts of addition and subtraction of whole numbers comprise one such content network. The features of this domain include:

1. The symbolic statements (e.g., $\underline{a}+\underline{b}=\underline{c}$ and $\underline{a}-\underline{b}=\underline{c}$; where $\underline{a}, \underline{b}$, and $\underline{c}$ are natural numbers) that characterize the domain are identified.

2. The implied task (or tasks) to be carried out is specified. For addition and subtraction, this involves describing the situations where two of the three numbers $\mathrm{a}, \mathrm{b}$, and $\mathrm{c}$ in the statements above are known and the other is unknown.

3. The rules (invariants) that can be followed to represent, transform, and carry out procedures to complete the task (e.g., find the unknown number using one or more procedure such as counting strategies, basic facts, symbolic transformations such as $\underline{\mathrm{a}}+[]=\underline{\mathrm{c}}<==>[]=\underline{\mathrm{c}}-\underline{\mathrm{a}}$, computational algorithms for larger numbers) all enumerated.

4. A set of situations that have been used to make the concepts, the relationships between concepts, and the rules meaningful (e.g., joinseparate, part-part-whole, compare, equalize, fair trading) is described.

The result of following the above steps yields a map (a tightly connected network) of the domain.

Some rules (or algorithms) for transforming symbols to other symbols are so useful that knowing them has been considered essential. In fact, mastery of many computational algorithms is considered by many to constitute mathematical 


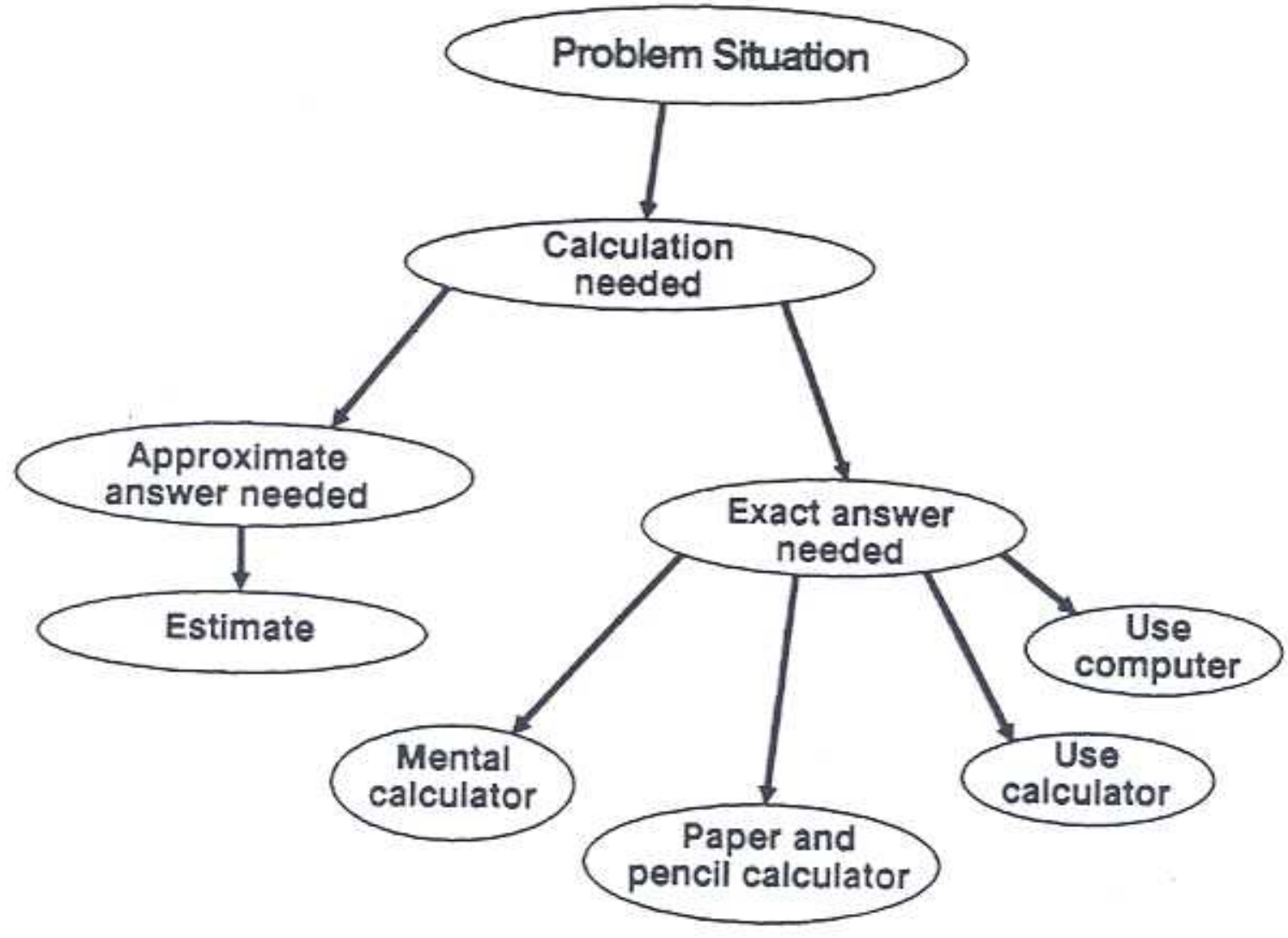

Figure 1. Decisions about how to calculate. 
knowledge. Knowledge of computational algorithms is important even at a time when calculators and computers perform most computations for us, but such knowledge should grow out of the problem situations that have given rise to the need for such algorithms. Furthermore, when one needs to calculate to find an answer to a problem one should be aware of the choices of methods that are appropriate (see Figure 1). Often an approximate answer is adequate, so one should estimate. If a precise answer is needed, then the choice is among several procedures. Many answers should be found by mental calculation (multiplying by 10 , taking half). Some calculations, if not too complex, should be done by following paper-and-pencil routines. For more complex calculations the calculator should be used (column addition, long division). And finally, if many iterative calculations are required, a computer program should be written or used to find answers. Note, contrary to the fears of many, the availability of calculators and computers has expanded a student's capability of performing calculations.

\section{Perspective 3: Reasoning}

A critical part of mathematics is that there are a set of intellectual methods that mathematicians use when developing conjectures, reasoning about phenomena, building abstractions, validating assertions, and solving problems. These thinking skills, or mathematical methods, are an important part of mathematics. However, in contrast to the previous two perspectives on mathematical literacy, these intellectual skills cut across all of the content networks. For example, no proposition in mathematics is considered a mathematical product until it has been validated. Initially, justifications may necessarily be built on empirical evidence, since they were based only on our perceptions. However, proof of an assertion through a rigorous, logical argument has become the hallmark of abstract mathematics. For example, no geometer who had measured the base angles of an isosceles triangle would conclude that they were congruent, no matter how accurate the measurements. Although such measurements may have formed the basis of a conjecture about congruence, mathematicians demand that the result be deduced from the fundamental concepts of geometry. Thus, mathematics involves ways of viewing and thinking about the world. The discipline grows by applying mathematical methods to a wide variety of problem situations. In this regard, to be mathematically literate, students need to make conjectures, abstract properties 
from problem situations, explain their reasoning, follow arguments, validate assertions, and communicate results in a meaningful form.

\section{Perspective 4: Applications of Mathematics}

The power of mathematical knowledge is that it is useful in many problem situations quite removed from those which originally gave rise to the mathematics. In fact, mathematics has become the foundation discipline for science and is now increasingly so for the social sciences as well. For example, logarithms, as described earlier, which were originally developed to make complex computations involving multiplication and division easier, have recently assumed new and more powerful applications. Even though calculations with logarithms are no longer useful because computers perform such calculations faster and more accurately, they are now a conceptual tool for evaluating algorithms in computer science, biological statistics, and a wide range of other fields. Also, while paper-and-pencil computational algorithms for such tasks as addition and subtraction are no longer the central focus of applied mathematics, the decision sequence involved in algorithms is an important conceptual tool that helps address structural properties of operations; this application has led to the study of operator algebras. In turn, the study of such operations has made it possible to simulate computationally a vast array of complex problems such as flow of blood through an artificial heart valve, the trajectory of a hurricane as it approaches a coastline, and tomographic images of the mantle of the earth. In fact, the building of mathematical models and the computational simulation of complex situations are now commonplace. As the sciences move increasingly toward computational methods, so too must the mathematics curriculum. Thus, mathematics is a foundation discipline for other disciplines and grows as a result of its utility. Hence, to be mathematically literate, students should be confronted with a variety of problems from other disciplines and have an opportunity to build mathematical models, structures, and simulations.

This picture of mathematical knowledge from the combination of the four perspectives on mathematical literacy is quite different from that experienced by students in typical classrooms where they most often work on sets of mathematical exercises to get correct answers. The important features of this new metaphor involve specifying domains of mathematical knowledge as interconnected networks of procedures, concepts, and methods of proof that grow 
as a result of confronting a variety of problem situations (empirical, abstract, and applied).

\section{THE NCTM CURRICULUM STANDARDS}

The best detailed description of the proposed curricular changes is currently being prepared by the National Council of Teachers of Mathematics. The draft document Curriculum and Evaluation Standards for School Mathematics (NCTM, 1987) is now in circulation for review. A final document will be available in early 1989. Three of the features of this document--goals, mathematical content, and methods of instruction--are summarized here.

\section{Goals and Assumptions}

The document begins with five general goals that should be reflected in mathematics curriculum standards across grades K-12. These are labeled (1) becoming a mathematical problem solver, (2) learning to communicate mathematically, (3) learning to reason mathematically, (4) valuing mathematics, and (5) becoming confident in one's ability to do mathematics. These goals imply that students should have numerous and various interrelated experiences that allow them to solve complex problems; to read, write, and discuss mathematics; to conjecture, test, and build arguments about a conjecture's validity; to value mathematical enterprise, mathematical habits of mind, and the role of mathematics in human affairs; and to be encouraged to explore, guess, and even make errors so that they gain confidence in their actions.

\section{Mathematical Content}

The goals in the draft document are followed by 50 standards- -37 on the mathematical content of the curriculum and 13 on evaluation. The curriculum standards are further subdivided into thirds representing major stages in a student's mathematical development. These stages roughly parallel the activities of the lower [K-4], middle [5-8], and high [9-12] school curricula. The desired outcomes for each of these levels of mathematics education represent changes from the current patterns.

At the $\mathrm{K}-4$ level the recommended standards assume that the primary focus of the curriculum should be on the development of mathematical understandings and relationships. Children acquire concepts with clarity and stability by 
constructing meanings in the context of physical situations, and abstractions emerge from empirical experience. Instruction must emphasize models and language to express mathematical ideas. Also, the curriculum content and instructional approaches should be consistent with the young child's level of cognitive and mathematical development. The curriculum should be aligned with children's capabilities in order for them to learn well. A developmentally appropriate curriculum incorporates real world contexts and children's experiences, uses children's language and viewpoints in developing content, provides sufficient time for children to construct meanings, and makes use of research evidence about children's mathematical thinking and learning.

At this level, the curriculum must take seriously the goal of developing students who possess confidence in their ability to think mathematically and solve problems; to demonstrate flexibility in working with mathematical ideas and problems; make appropriate decisions in selecting strategies and techniques; recognize familiar mathematical structures in unfamiliar settings; detect patterns; and to analyze data. Young children are active individuals who construct and modify ideas and integrate existing knowledge through interacting with the physical world, materials, and other children.

To be mathematically literate, students in K-4 need to possess knowledge of the domains in such important branches of mathematics as measurement, algebra, geometry, statistics, and probability. Mathematical ideas grow and expand as children work with them throughout the curriculum. The informal approach at this level establishes the foundation for further study and permits children to acquire the additional knowledge they need. Children need to understand how mathematical ideas are interrelated. Number concepts can be discussed in the context of measurement. Geometric models can be used to clarify number ideas. Patterns can be explored through work with numbers and operations. Graphs can be part of work with measurement or number concepts, and problems can be selected that involve several mathematical ideas.

At the 5-8 level it is assumed that computation is but one of many basic skills and is a mathematical process that can best be accomplished through the use of technology. In fact, the calculator renders obsolete much of the computational proficiency emphasized in traditional courses. Other mathematics such as estimation, geometry, probability, and statistics are increasingly more important and, with the help of technology, more accessible. 
Middle school children can rightly be called "children in transition." Vast changes occur in their intellectual, psychological, social, and physical development. They abound with restless energy, respond to peer influence, and are curious about themselves. Self-consciousness is the hallmark of middle school children. Teachers need to provide a caring environment in which students can feel free to explore mathematical ideas, to ask questions, to discuss their ideas, and to make mistakes. Listening to students' ideas and encouraging students to listen to one another establishes an atmosphere of mutual respect.

Also, during grades 5-8, students begin to develop their abilities to think and reason more abstractly. Concrete experiences continue to provide the means by which they construct knowledge. From these experiences they abstract more complex meanings and ideas. Opportunities for students to discuss and write about their ideas should accompany these experiences. Discussions can help students clarify their thinking as well as formulate and verify mathematical conjectures.

Grades 5-8 are crucial in the transition to adulthood. This is a time when lifelong values are being formed. Students make decisions about what they will study and their approach to learning, decisions that can dramatically affect their future. Failure to study mathematics can close the door to many college majors and careers, and the lack of mathematics has especially affected young women and minority students. It is during the middle grades that the attitudes are formed that affect these decisions. Students solidify their notions about what they like and do not like. It is crucial that conscious efforts be made to encourage all students. To this end the curriculum must be of interest to students and must emphasize the usefulness of mathematics.

At the 9-12 level it is assumed that arithmetic computation should not be a direct object of study. Conceptual and procedural understandings of number, numeration, and operations and the ability to make estimations and approximations and to judge the reasonableness of results will be strengthened. Students will work in the context of applications and problem solving, including those situations dealing with issues of scientific computation.

In summary, as the curriculum standards were being written, the mathematical content that students should have an opportunity to learn was the initial consideration. 


\section{Methods of Instruction}

The second part of each standard produced by NCTM lists important actions expected of students. These actions are expected to result from engagement in specific instructional activities. Two general principles guide the development of activities: first, instructional activities grow out of problem situations; and second, learning occurs by construction, not absorption.

Traditional teaching emphases on practice in notational transformations and solution algorithms as necessary precursors to coping with a problem ignore the fact that knowledge emerges from the problems. This fact suggests that, instead of the expectation that skill in computation should precede word problems, experience with problems helps develop the ability to compute. Thus, present strategies for teaching mathematics by first teaching skills and then exposing students to stylized application problems need to be reversed; knowledge should emerge from experience with problems.

A genuine problem is a situation in which, for the individual or group concerned, one or more appropriately analogous strategies have yet to be developed. The situation should be complex enough to offer challenge but not so complex as to be cooperatively insoluble by the group of students. In fact, problem situations should parallel the kind of phenomena for which mathematical structures have been typically created (Freudenthal, 1983). Thus, pupils need to experience the phenomena for which such concepts, structures, and ideas were created. In order to teach the mathematizing of situations, teachers need to create suitable contexts; the most abstract mathematics needs the most concrete contexts.

In most classrooms, the conception of learning is that students are passive absorbers of information, storing it in easily retrievable fragments as a result of repeated practice and reinforcement. Research findings from psychology indicate that learning does not occur by passive absorption (Resnick, 1987). Instead, individuals approach each new task with prior knowledge, assimilate new information, and construct their own meanings. For example, before young children are taught addition and subtraction, they can already solve most addition and subtraction problems using such routines as "counting on" and "counting back" (Romberg \& Carpenter, 1986). As instruction proceeds, children often continue to use these routines to solve problems, in spite of being taught more formal procedures. They will only accept new ideas when their old ideas do not work or 
are inefficient. Furthermore, ideas are not isolated in memory but are organized and associated with the natural language that one uses and the situations one has encountered in the past. This constructive, as opposed to passive, view of the learning process must be reflected in the way mathematics is taught. Instruction based on this conception of learning is different from that in the typical mathematics classroom where the teacher is transmitting lessons through exposition to a captive audience. Instruction from this perspective should include project work rather than exercises; group assignments as well as independent work, discussions about the origin of and relationships among concepts, and intrinsic motivation through curiousity.

These ideas about problem situations and learning are reflected in the verbs used to describe student actions (e.g., to investigate, to formulate, to find, to verify). These verbs describe student work on different types of problems. Although each problem situation is in some sense unique, we have considered them under seven general headings. While each category of actions is different in an important way from the others, all are closely related.

Examine. Many of the activities, particularly those used in introducing new content, involve examining or exploring some situation. The purpose of such activities is to abstract or to invent. To abstract means to identify the intrinsic form or essence, shape or structure of a given situation. To invent means to produce for the first time through the use of one's imagination, ingenious thinking, or experimentation. Pattern recognition is at the heart of mathematical thinking, and invention is so intimately linked with abstraction as to be inseparable. Labels (terms, signs, or symbols) are invented to represent most abstractions. An essential part of these activities is negotiation with students about the choice and purpose of such labels.

Represent. In activities of this type, students form or produce an image, picture, word, sentence, chart, or table using appropriate symbols for the referents in a problem situation. Making representations is part of the process of learning to construct mathematical models of problem situations.

Transform. A transformation involves changing one expression into another following one or more rules. Much textbook mathematics involves learning how to perform transformations. Examples include computational algorithms, division of polynomials, and transforming from one representation to another, such as from an algebraic description of a function to a geometric representation as a graph. 
Students need to understand why such transformations are desirable and how to perform the changes, even though rapid proficiency may no longer be essential.

Prove. When students have made conjectures about a situation, they need to establish evidence that compels acceptance of their propositions. The kind of evidence and form of argument may vary, as mentioned earlier, but the intent remains constant. Students should be able to construct cogent arguments in support of their claims. Depending on the problem situation, their arguments may be based on empirical evidence, inductive queries, and deductive chains of reasoning.

Apply. To apply is to use known concepts and procedures in new situations. In applying, one might invent; in the process of inventing, one might apply; and, as a precursor to inventing, one might abstract.

Solve problems. This category refers to true problem-solving situations. Complex situations are presented to students who have acquired the necessary concepts and procedures to find a solution but need to use some strategies (heuristics) to make the connections between the given information and a method of solution.

Communicate. This category of activities involves exchange of information between individuals by use of a common symbol system. Thus, students should be given numerous opportunities to express mathematical ideas verbally and in writing and to comprehend and interpret ideas expressed by others.

As students' mathematical power grows and changes, the problem situations must vary with the maturity--both mathematical and cultural--and experience of the students. For example, the primary grades should emphasize the empirical language of the mathematics of whole numbers, common fractions, and descriptive geometry. In the middle grades, the empirical mathematics should be extended to other numbers, and the emphasis should shift to building the abstract language of mathematics needed for algebra and other aspects of mathematics. High school mathematics should emphasize functions, their representations and uses, modeling, deductive proofs, and applications.

In summary, the NCTM standards specify that instruction should be based on problem situations. As long as the situations are familiar, conceptions are created from objects, events, and relationships in which operations and strategies are well understood. In this way, students develop a framework of support that can be drawn upon in the future, when rules may well have been forgotten but the 
Students need to understand why such transformations are desirable and how to perform the changes, even though rapid proficiency may no longer be essential.

Prove. When students have made conjectures about a situation, they need to establish evidence that compels acceptance of their propositions. The kind of evidence and form of argument may vary, as mentioned earlier, but the intent remains constant. Students should be able to construct cogent arguments in support of their claims. Depending on the problem situation, their arguments may be based on empirical evidence, inductive queries, and deductive chains of reasoning.

Apply. To apply is to use known concepts and procedures in new situations. In applying, one might invent; in the process of inventing, one might apply; and, as a precursor to inventing, one might abstract.

Solve problems. This category refers to true problem-solving situations. Complex situations are presented to students who have acquired the necessary concepts and procedures to find a solution but need to use some strategies (heuristics) to make the connections between the given information and a method of solution.

Communicate. This category of activities involves exchange of information between individuals by use of a common symbol system. Thus, students should be given numerous opportunities to express mathematical ideas verbally and in writing and to comprehend and interpret ideas expressed by others.

As students' mathematical power grows and changes, the problem situations must vary with the maturity--both mathematical and cultural--and experience of the students. For example, the primary grades should emphasize the empirical language of the mathematics of whole numbers, common fractions, and descriptive geometry. In the middle grades, the empirical mathematics should be extended to other numbers, and the emphasis should shift to building the abstract language of mathematics needed for algebra and other aspects of mathematics. High school mathematics should emphasize functions, their representations and uses, modeling, deductive proofs, and applications.

In summary, the NCTM standards specify that instruction should be based on problem situations. As long as the situations are familiar, conceptions are created from objects, events, and relationships in which operations and strategies are well understood. In this way, students develop a framework of support that can be drawn upon in the future, when rules may well have been forgotten but the 
structure of the situation remains embedded in memory, a foundation for reconstruction. Situations should be sufficiently simple to be manageable, but sufficiently complex to provide for diversity in approach. They should be amenable to individual, small-group, or large-group instruction, involve a variety of conceptual domains, and be open as to the methods to be used. 


\section{APPROPRIATE INDICATORS}

The question being posed in this section is, "How valid is the information about mathematics knowledge gathered via current procedures?" The ease of development, the convenience, and low cost of standardized tests and profile achievement tests has made the scores derived from them the common indicators used in American schools. The validity of such scores, however, is now being questioned.

\section{STANDARDIZED TESTS}

Norm-referenced standardized tests, including the well-known ACT and SAT used in college admission decisions, have become part of the yearly ritual in most schools. The purpose of such tests is to rank order respondents with respect to a particular type of mental ability or achievement, thus indicating a respondent's position in a population. Scores derived from these tests are used to make selection and placement decisions. Each test is comprised of a set of independent multiple choice questions. The items have necessarily been subjected to a preliminary tryout with a representative pupil group so that they could be arranged in the desired manner with respect to difficulty and the degree to which they discriminate among students. Also, the test is accompanied by the appropriate table for transforming counts of items correct into meaningful characterizations of pupil mental ability or achievement such as grade-equivalent scores, percentiles, or stanines.

There are four features of such tests that need to be commented upon. First, although each test is designed to order individuals on a single (unidimensional) trait, such as quantitative aptitude, the derived score is not a direct measure of that trait. It is like reporting a measure of San Francisco's basketball star Ralph Sampson's height not as 7' 4", but as at the 99th percentile for American men.

Second, because individual scores are compared with those of a norm population, there will always be some high and some low scores. This is true even if the range of scores is small. Thus, high and low scores cannot be judged as "good" or "bad" with respect to the underlying trait.

Third, the items on the test are assumed to be equivalent to each other. 
They are selected on the basis of general level of difficulty and some index of discrimination. However, there is no claim that the items are representative of any well-defined domain. For example, in many subtraction computation standardized tests, several items such as that shown in Figure 2 are common. Because of a zero in the minuend place, such an item requires successive regroupings and discriminates between good and average subtractors. However, if one were to randomly generate three-digit subtraction problems, those with zeros in the minuend would appear infrequently.

$\begin{array}{ccc}304 & \text { A) } & 272 \\ -176 & \text { B) } & 138 \\ & \text { C) } & 238 \\ & \text { D) } & 128 \\ & \text { E) } & 232\end{array}$

Figure 2. A typical three-digit subtraction test item.

Finally, the validity of such tests is predictive validity. Scores on the Scholastic Aptitude Tests (SATs) are useful because they are reasonable predictors of how well students will do at college.

The strength of standardized tests is that they do what they were designed to do reasonably well. They are relatively easy to develop and are inexpensive and convenient to administer. Furthermore, the results are comprehendible since standard procedures are followed.

Their primary weakness is that they are often used for decisions they were not designed to address. For example, aggregating standardized scores for students in a class (school, district, or other unit) to get a class profile of achievement or mean is a very inefficient method of profiling. Standardized test scores provide too little information for the cost involved. Similarly, their use is of little value for judgements about curricular change, since the items are not selected to be representative of the mathematical domains in the curriculum. Unfortunately, their use appears to be more strongly related to political rather than educational uses. For example, it is claimed that elected officials and educational administrators increasingly use the scores from such tests in 
comparative ways--to indicate which schools, school districts, and even individual teachers give the appearance of achieving better results (National Coalition of Advocates for Students, 1985). Such comparisons are misleading. One can only conclude that standardized tests are unwisely overused.

Finally, no claim for validity with respect to mathematical literacy can be made. Items in standardized tests are assumed to reflect equivalent but independent concepts and procedures rather than the structured, interdependent ideas of mathematics.

\section{PROFILE ACHIEVEMENT TESTS}

Profile tests have become very popular alternatives to standardized tests. They have been developed for several major studies of mathematical performance such as the National Longitudinal Study of Mathematical Abilities (NLSMA), National Assessment of Educational Progress (NAEP), First International Mathematics Study (FIMS), Second International Mathematics Study (SIMS), and several state assessments.

In contrast to standardized tests, profile achievement tests are designed to yield a variety of scores for groups of students. As early as 1931, Ralph Tyler outlined a procedure for test construction and validation that clearly pointed out the essential dependence of a program of achievement testing on the objectives of instruction; he also recognized a variety of forms of pupil behavior indicating attainment of the desired instructional outcomes. Perhaps he more than any other single test specialist was responsible for the extension of achievement testing to the outcomes of instruction. His contributions over fifty years ago doubtless did much to introduce the broad modern conception of evaluation to replace the narrower concept of standardized testing. Profile tests are intended to provide information on a variety of topics so that educators and policymakers can compare individuals or groups in those topics.

The typical approach to profile testing is to specify a content by behavior matrix. Within this matrix, matrix sampling is followed for the actual test administration; that is, in each cell of the matrix, items are sampled so that each student tested takes only a portion of the total items. For example, for the Second International Mathematics Study (SIMS; Weinzweig \& Wilson, 1977) a context $\mathrm{x}$ behavior grid was developed for the grade 8 and grade 12 target populations. The content dimensions were intended to cover all of the topics 
likely to be taught in any country. For grade 8 , the content outline contained 133 categories under five broad classifications: arithmetic, algebra, geometry, statistics, and measurement. For grade 12, the content description was broader. It contained 150 categories under seven headings: sets and relations, number systems, algebra, geometry, elementary fractions and calculus, probability and statistics, and finite math.

For each population in the SIMS study, the behavior dimension referred to four levels of cognitive complexity expected of students--computation, comprehension, application, and analysis. This classification was adapted from Bloom's Taxonomy of educational objectives (1956). The adaptation involved replacing knowledge in Bloom's Taxonomy with computation and not using the higher levels of synthesis and evaluation. Both adaptations cause problems. First, computation means knowledge of and ability to carry out a routine algorithm or procedure; however, knowledge of basic concepts does not fit well as either computation or comprehension. Second, eliminating the two higher levels of Bloom's taxonomy constitutes an admission that important aspects of problem solving and developing a logical argument about a conjecture cannot be assessed.

Items similar to those in standardized tests were prepared for each cell of the matrix. Data then were reported in several ways. First, they were reported in terms of items or cell means. Second, item scores were aggregated by columns to yield cognitive level scores or by rows to yield topic scores.

Four features of profile assessments make them quite different from standardized tests. First, there is no assumption of an underlying single trait. The tests are designed to reflect the multidimensional nature of mathematical content. There is often a temptation to aggregate across topics to get a single total score; such a score would be very misleading. Second, the unit of investigation is a group, not an individual; matrix sampling allows a wide variety of items to be given in relatively little time for each person. Third, comparisons between groups are done graphically on actual scores. No transformations are needed. Finally, validity is determined in terms of content and/or curricula validity. Mathematicians and teachers are asked to judge whether individual items reflect a content behavior cell in the matrix and sometimes to judge whether or not the item represents something that was actually taught.

The strength of profile achievement tests is that they can provide useful information about groups. They could be useful for general evaluations of 
changed educational policy that directly affects classroom instruction, if they were repeatedly administered so that change could be estimated.

There are five weaknesses of these tests. First, because they are designed to reflect group performance, they are not useful for individual ranking or diagnosis; with matrix sampling an individual student takes only a sample of items. Second, they are somewhat more costly to develop than standardized tests and harder to administer and score. Third, because they yield a profile of scores, they are hard to interpret. Fourth, in the past they usually have not been administered often enough to produce scores that could be compared to indicate change over time. The most serious weakness these tests is in the outdated assumptions underlying both dimensions of content by behavior matrices. The content dimension involves a classification of mathematical topics into "informational" categories. As Romberg (1983) has argued:

"Informational knowledge" is material that can be fallen back upon as given, settled, established, assured in a doubtful situation. Clearly, the concepts and processes from some branches of mathematics should be known by all students. The emphasis of instruction, however, should be "knowing how" rather than "knowing what." (p. 122)

Furthermore, the items in any content category are tested as if they were independent of each other. This ignores the interconnections between ideas within a domain. Schoenfeld and Herrmann (1982) cautioned about testing students on isolated tasks.

If they succeed on those problems, we and they congratulate each other on the fact that they have learned some powerful mathematical techniques. In fact, they may be able to use such techniques mechanically while lacking some rudimentary thinking skills. To allow them, and ourselves, to believe that they understand the mathematics is deceptive and fraudulent. (p. 29)

Thus, the items should reflect the actual interdependence (rather than independence) of ideas in a content domain.

The behavior dimension of matrices has always posed problems. Bloom's Taxonomy (1956) has proven to be useful for low level behaviors (knowledge, comprehension, and application) but difficult for the higher levels (analysis, 
synthesis, and evaluation). Single-answer multiple-choice items are not reasonable for those levels. In addition, the Taxonomy suggests, contrary to current psychological thinking, that the "lower" skills should be taught before the "higher" skills. It is based on "the naive psychological principle that individual simple behaviors become integrated to form a more complex behavior" (Collis, 1987, p. 3). In the past 30 years, our knowledge about learning and how information is processed has changed and expanded.

In summary, profiling has advantages, but current profile tests fail to reflect the way mathematical knowledge is structured or how information is processed within those mathematical domains.

The main point to be made is that, while these two testing procedures are useful for some purposes and undoubtedly will continue to be used, they are products of an earlier era in educational thought. Like the Model T Ford assembly line, objective tests were considered an application of modern scientific techniques in the $1920 \mathrm{~s}$. Today we ought to be able to do something better.

\section{A NEW APPROACH TO INDICATORS}

A new set of assessment strategies needs to be developed so that valid information is available for decision making. One promising approach is to follow a "domain knowledge" strategy. For a particular mathematical domain, as described on pages 14 and 15 , a valid index needs to be developed. Thus, one would expect to:

1. identify a small number of important conceptual domains in mathematics and identify a map of each domain;

2. develop a set of tasks that are related to the key features in each domain;

3. administer the tasks to groups of students;

4. from the responses to the tasks, logically combine information to yield a score that should reflect a student's maturity with that domain;

5. for each individual or group, construct a score vector over all of the domains (e.g., John $\left[\underline{X}_{1}, \underline{X}_{2}, \ldots, \underline{X}_{n}\right]$ where $\underline{X}_{i}=$ score for a domain).

The domain of multiplication is used here to illustrate how to construct such an index. Multiplication involves a set of problem situations in which the implied 
relationships between the magnitudes expressed in each situation can be represented by a multiplicative expression $\underline{\mathrm{a}} \times \underline{\mathrm{b}}=\underline{\mathrm{c}}$, where $\underline{\mathrm{a}}, \underline{b}$, and $\underline{\mathrm{c}}$ are numbers and $x$ is an operation on numbers with certain properties. Thus, the most important feature of the domain is the connection between the problem situation and its multiplicative representation. It is important for students to comprehend the differences between these situations and those which are represented with additive expressions $(\underline{a}+\underline{b}=\underline{c})$. Four common situations are represented by multiplication:

- Grouping (and partitioning): 4 dozen eggs is $4 \times 12=\underline{\mathrm{e}}$.

- Area (or array): The area of a rectangle whose width is $7 \mathrm{ft}$. and length is $5 \mathrm{ft}$. is $\underline{A}=7 \times 5$.

- Simple linear functions (ratios): If one usually mixes 3 cans of orange juice with a gallon of water the number of cans of orange juice needed with 5 gallons of water is $3 / 1=\underline{c} / 5$.

- Combinatorics: The number of different double dip cones that can be made from five flavors of ice cream is $\underline{N}=2 \times 5$.

The computational task in all situations is to find the value of $\underline{a}, \underline{b}$, or $\underline{c}$ if two magnitudes are given (e.g., find distance, $\underline{\mathrm{d}}$, if $\underline{\mathrm{d}}=\underline{\mathrm{r}} \times \underline{\mathrm{t}}$ and rate, $\underline{\mathrm{r}}$, and time, $\mathrm{t}$, are known).

Two features make developing an index complex: First, in most problem situations it is impossible to separate the operations of multiplication and division, and, in fact, one wants students to see the integral relationships between the operations. For example, if $\underline{d}$ and $\underline{\mathrm{r}}$ were known in the functional situation above, the task would be to find $\mathrm{t}$. This can be done by knowing what number one must multiply $\underline{I}$ by to get $\underline{\mathrm{d}}$; however, it is best done by division. (Note the similarity to the relationship between addition and subtraction.)

Second, students should demonstrate mastery of the properties of this operation--memorization of basic facts; understanding that $\underline{\mathrm{a}} \times 1=\underline{\mathrm{a}}$, $\underline{\mathrm{a}} \times 0=0$, $\underline{\mathrm{a}}$ $\mathrm{x} \underline{\mathrm{b}}=\underline{\mathrm{b}} \times \underline{\mathrm{a}}, \underline{\mathrm{a}} \times(\underline{\mathrm{b}}+\underline{\mathrm{c}})=\underline{\mathrm{a}} \times \underline{\mathrm{b}}+\underline{\mathrm{a}} \times \underline{\mathrm{c}}$; showing graphically that, if $\underline{\mathrm{r}}$ is constant, $\underline{\mathrm{d}}=\underline{\mathrm{I}} \times \mathrm{t}$ is a linear relationship; describing the steps in carrying out (or programming) a multiplication algorithm.

Given this description of the domain, assessment questions would need to be constructed for the following key student outcomes: 
1. Represent problem situations with multiplicative sentences;

2. Write a correct representation for such situations;

3. Decide whether an exact or approximate answer is needed and (a) estimate if an approximate answer is needed, or (b) decide which procedure (mental, paper-and-pencil, calculator, or computer) is appropriate if an exact answer is needed;

4. Carry out the appropriate procedure;

5. Judge the reasonableness of results of the procedure;

6. Argue the validity of an answer in terms of the context of the given problem situation; and

7. Discuss the properties of multiplication in contrast to other operations on numbers.

Tasks for assessment purposes then would be of two types: Some would be wholely in the formal mathematical system to ascertain whether students know the symbols, relationships, and rules; others would be given as problem situations that reflect the hypothesized progression described above.

Since all actual calculation involves only basic facts and concepts about place value, unit fractions, direction, and so on, assessment should start with small whole numbers and include whole numbers, fractions, decimals, and integers.

Tasks would be administered in a combination of ways. Not only would standard group testing be used, but individually administered performance tests and even small group cooperative tests should be possible. What is important is that the administration procedure be appropriate for the type of problem situation.

The form of the responses, thus, must also vary. In particular, since one is often interested in the strategy a student has used to work a problem, an open ended response form to tasks would often be appropriate. Also, the rules one uses to judge responses will be complex; they must include both the correctness of a response and the appropriateness of the strategy used for the particular problem situation. The aggregation of responses would be designed to estimate the progress of an individual or a group in the domain; the aggregation will not be a simple sum, but a logical combination of information.

Although it may take years before current testing procedures are replaced in 
schools, we should be looking at plausible alternatives. Our task is not to write cleverer test items of the same type (independent, single answer, multiple choice) but to write other kinds of questions based on this new conception of domain knowledge. We need questions that give students an opportunity to think like a mathematician--reflect, organize, model, represent, argue. In addition, these questions should be structured so that students' knowledge of the interrelationships between ideas within specific mathematical domains can be determined. Constructing, scoring, scaling, and interpreting responses to such items will not be easy, but in the long run they will be worth the effort. 


\section{IMPLEMENTATION OF CHANGES}

The changes in curricula, instructional techniques, and indicators that are being proposed by the mathematical sciences education community will not be easy to implement. There are many reasons for the probable difficulties; too many to discuss in detail in this paper. However, three need to be mentioned: the coherence of the current educational system, the "zero-sum" assumed consequences of any change, and the legacy of the "modern-math" experience.

\section{COHERENCE OF THE EDUCATIONAL SYSTEM}

The current system of schooling is a coherent system. It may be out-ofdate and inappropriate, but all participants (students, teachers, administrators, and parents) understand their roles and responsibilities; procedures have been developed over a long period of time; rules and regulations have been worked out. The changes being proposed challenge traditional practices and beliefs about schooling and school mathematics. The most important barriers to reform are the beliefs, expectations, and attitudes strongly held by all persons involved in education in relation to specific aspects of the reform. For example, a teacher who believes that speed in paper-and-pencil calculation is important is going to be reluctant to let children use calculators. The administrator who has charted group scores on a standardized test for years is going to be reluctant to replace it. The college admissions official who expects transcripts with the course titles Algebra and Geometry will be disturbed. Parents who expect mathematics homework to be done at a desk on paper, rather than by gathering real data for some problem, will be surprised. The proposed changes are a direct challenge to perceptions held by many persons about the content of mathematics, about what is important for students to learn, about the job of teaching, about what constitutes the work of students, and about the professional roles and responsibilities of teachers and administrators.

A second barrier to change is the common attitude of organizations toward change--namely, resistance. Changing schooling practices has proven to be difficult during the past quarter century (Dalin, 1978). It is easy to be inactive by waiting for the storm to pass, or to make nominal change by changing labels rather than changing practices, as many did with "modern math" (Romberg \& 
Price, 1983). It is all too easy to agree with the rhetoric of reform but maintain at the same time long-held beliefs or practices in the face of questions about those beliefs and practices.

A third barrier to change is the failure of many to see that the reform being proposed means building a new system, not just altering a few parts. Expecting students to work arithmetic problems with calculators changes tests as well as daily lessons. Including a unit on exploratory data analysis in a junior high program acquires that appropriate materials are available.

The fourth barrier involves the political framework within which schools operate. Policy decisions about schooling are made by elected representatives at the federal, state, and local levels and are operationalized in administrative directives. Many of the needed changes can only be fully implemented by changing many directives about selection of texts, statewide testing, and so forth. Policymakers must change the rules.

Still another barrier to reform is cost. Excellence costs money. Most schools, like the communities they serve, are surviving but not thriving. Any reform requires considerable time, commitment, and resources to be successful. Resources are scarce; yet they must be found and used judiciously. School boards and administrators must be prepared to support the technology of school mathematics in the same way they now support the teaching of science, physical education, or industrial arts.

In summary, lasting change will only occur if another coherent system is created, a system appropriate for an information society, as an alternative to the current industrially based system.

\section{THE "ZERO-SUM" CONSEQUENCE OF CHANGE}

In a system such as an auto assembly line, if something is "added" to the line (e.g., a new accessory), then either the system expands or something is "subtracted." If an aspect of the system is set, like the time for mathematics in schools, some would argue that if something is added something else must be dropped to yield a "zero-sum." While many interested in school mathematics may agree that statistics or discrete math should be included in the curriculum, they want to know what will be dropped. In fact, many are concerned that their "favorite" math topic will be one of those to be deleted.

At face value this argument seems logical. However, let us examine two 


\section{IMPLEMENTATION OF CHANGES}

The changes in curricula, instructional techniques, and indicators that are being proposed by the mathematical sciences education community will not be easy to implement. There are many reasons for the probable difficulties; too many to discuss in detail in this paper. However, three need to be mentioned: the coherence of the current educational system, the "zero-sum" assumed consequences of any change, and the legacy of the "modern-math" experience.

\section{COHERENCE OF THE EDUCATIONAL SYSTEM}

The current system of schooling is a coherent system. It may be out-ofdate and inappropriate, but all participants (students, teachers, administrators, and parents) understand their roles and responsibilities; procedures have been developed over a long period of time; rules and regulations have been worked out. The changes being proposed challenge traditional practices and beliefs about schooling and school mathematics. The most important barriers to reform are the beliefs, expectations, and attitudes strongly held by all persons involved in education in relation to specific aspects of the reform. For example, a teacher who believes that speed in paper-and-pencil calculation is important is going to be reluctant to let children use calculators. The administrator who has charted group scores on a standardized test for years is going to be reluctant to replace it. The college admissions official who expects transcripts with the course titles Algebra and Geometry will be disturbed. Parents who expect mathematics homework to be done at a desk on paper, rather than by gathering real data for some problem, will be surprised. The proposed changes are a direct challenge to perceptions held by many persons about the content of mathematics, about what is important for students to learn, about the job of teaching, about what constitutes the work of students, and about the professional roles and responsibilities of teachers and administrators.

A second barrier to change is the common attitude of organizations toward change--namely, resistance. Changing schooling practices has proven to be difficult during the past quarter century (Dalin, 1978). It is easy to be inactive by waiting for the storm to pass, or to make nominal change by changing labels rather than changing practices, as many did with "modern math" (Romberg \& 
Price, 1983). It is all too easy to agree with the rhetoric of reform but maintain at the same time long-held beliefs or practices in the face of questions about those beliefs and practices.

A third barrier to change is the failure of many to see that the reform being proposed means building a new system, not just altering a few parts. Expecting students to work arithmetic problems with calculators changes tests as well as daily lessons. Including a unit on exploratory data analysis in a junior high program acquires that appropriate materials are available.

The fourth barrier involves the political framework within which schools operate. Policy decisions about schooling are made by elected representatives at the federal, state, and local levels and are operationalized in administrative directives. Many of the needed changes can only be fully implemented by changing many directives about selection of texts, statewide testing, and so forth. Policymakers must change the rules.

Still another barrier to reform is cost. Excellence costs money. Most schools, like the communities they serve, are surviving but not thriving. Any reform requires considerable time, commitment, and resources to be successful. Resources are scarce; yet they must be found and used judiciously. School boards and administrators must be prepared to support the technology of school mathematics in the same way they now support the teaching of science, physical education, or industrial arts.

In summary, lasting change will only occur if another coherent system is created, a system appropriate for an information society, as an alternative to the current industrially based system.

\section{THE "ZERO-SUM" CONSEQUENCE OF CHANGE}

In a system such as an auto assembly line, if something is "added" to the line (e.g., a new accessory), then either the system expands or something is "subtracted." If an aspect of the system is set, like the time for mathematics in schools, some would argue that if something is added something else must be dropped to yield a "zero-sum." While many interested in school mathematics may agree that statistics or discrete math should be included in the curriculum, they want to know what will be dropped. In fact, many are concerned that their "favorite" math topic will be one of those to be deleted.

At face value this argument seems logical. However, let us examine two 
consequences of this position. First, choice of what should be taught depends on what one values. Many parents are disappointed if students do not have the kinds of schooling experiences they fondly recall. Unfortunately, such experiences are not necessarily good guides for determining what today's students should be taught. It is critical to decide on what is to be taught based on what is of fundamental value for students so they may live in the different, information world of the 21st century.

Second, the "zero-sum" argument is only totally valid if one is only changing parts of the system. It does not hold if one is restructuring the system. The changes discussed in the preceding sections call for a radical restructuring of the mathematics curriculum. Given current research on learning it may even be possible that, "by emphasizing problem solving without abandoning computation, we can improve both skills, in effect making the curriculum a 'positive-sum game" (Kirsner, 1988).

\section{THE "MODERN MATH" LEGACY}

It is only natural that calls from the mathematics community for curricular reform bring to the minds of many educators and the public the "modern math" movement that began over 30 years ago. That movement was based in part on the notion that by learning the underlying structures of mathematics students would gain an understanding of mathematical techniques. That movement is remembered as a disaster by the public. Although this perception is not entirely accurate, the impact of "modern math" on school mathematics must be judged as a failure. However, we ought to be clear both about why "modern math" failed and how the current "math literacy" movement is different,

According to Howe (1987) "modern math" failed for the following reasons. First, in many countries the reform was led by academic mathematicians, with little participation by practicing teachers. Second, the content of the new mathematics curriculum was too different from the mathematics that teachers and parents were used to. It didn't relate to what they knew about; instead, it introduced abstract ideas, concepts, and methods that appeared quite alien. Third, the new mathematics made too heavy demands on classroom teachers, requiring them to learn new content and new methods and to develop new kinds of assessment techniques. Fourth, it ran afoul of growing political conservatism in the late seventies and early eighties that advocated a "back to basics" approach in 
mathematics education. Fifth, it did not stay in step with the changes in society over the period; in particular it did not take account of the significant new techniques that computers were bringing to applied mathematics (p. 218).

The changes in school mathematics being argued for in this paper have their origins in the economic needs of society. Thus, the calls for reform originated in the business community and not from pure mathematicians. The audience for the changes today is all students, not just those who might aspire to become mathematicians. Furthermore, the changes are aimed at making mathematics more understandable and useful not more abstract. In addition, the proposed changes are rooted in the technological changes which are currently changing our society. While the demands on teachers are considerable, the change strategy that is being followed involves professional development rather than administrative directives.

It is this last point that gives greatest hope that reform in the mathematics curriculum will receive widespread acceptance. Professional development implies the direct involvement of the professional organizations in setting goals and describing a vision of the mathematics curriculum and instruction without being prescriptive about how to achieve that vision. In this spirit the NCTM Curriculum and Evaluation Standards (1987) were prepared. This document lists what should be valued and calls on all to help. In this sense the approach is to help teachers and other educators, via their professional organizations, become empowered to make changes.

The barriers to change could be seen as insurmountable, or they could be seen as challenges to be met and overcome. A new school mathematics program needs to be developed and implemented. The content that should be included in a school mathematics program has been specified. Materials such as texts, courseware, and tests can be produced so that constructive learning will take place in classrooms. However, let it be understood that no illusions of immediate reform are held; it will only be accomplished by hard work. The hope and expectation is that there are a sufficient number of persons willing to work so that the reform is accomplished. 


\section{CONCLUSION}

The quality of instruction in the classrooms of this nation has always been a reflection of society at large. Improvement will result only from a different perception of mathematics, of appropriate student activities, and of teacher roles and from different expectations by the many segments of society. Hence, improving school mathematics is dependent on changing understandings on the part of all of society.

In this paper the case for radical reform in school mathematics has been presented. Although the curriculum should include more and somewhat different mathematics for all students, the real change in content should involve a shift in emphasis from procedural skills to conceptual understanding. Instruction should focus on problem situations in which students have an opportunity to explore, make conjectures, communicate their ideas, and provide reasons. Teachers should be supportive guides as students examine problems. They should be able to provide students with a wide range of activities and be able to judge their growth in mathematical thought such as use of strategies and kind of reasoning. Furthermore, for accountability purposes procedures must be developed which reflect the maturity of student thinking in specific mathematical domains. Finally, while there are many barriers to reform, the professional development strategy being followed makes it the responsibility of all involved and interested in school mathematics to become proactively involved in making reform happen.

Collectively we have a rare opportunity to make real, substantive changes in school mathematics so that all students possess both a suitable and a sufficient mathematical background to be productive citizens in the next century. 


\section{REFERENCES}

Albers, D. J., Anderson, R. D., \& Loftsgaarden (1987). Undergraduate programs in the mathematical and computer sciences the 1985-1986 survey. Washington, DC: Mathematical Association of America.

Anick, C. M., Carpenter, T. P., \& Smith, C. (1981). Minorities and mathematics: Results from the National Assessment of Educational Progress. Mathematics Teacher, 74, 560-566.

Bloom, B. S. (Ed.). (1956). Taxonomy of educational objectives: The classification of educational goals. Handbook 1. Cognitive domain. New York: Longmans, Green, \& Company.

Bobbitt, F. (1924). How to make a curriculum. Boston: Houghton Mifflin.

Carpenter, T. P., Brown, C., Kouba, V., Lindquist, M. M., Silver, E. A., \& Swafford, J. O. (1987). Results from the Fourth Mathematics Assessment of the National Assessment of Educational Progress. Reston, VA: National Council of Teachers of Mathematics.

Charters, W. W. (1923). Curriculum construction. New York: Macmillan.

Collis, K. F. (1987). Levels of reasoning and the assessment of mathematical performance. In T. A. Romberg (Ed.), The monitoring of school mathematics: Background papers. Vol. 2: Implications from psychology:

outcomes of instruction, pp. 203-224. Madison: Wisconsin Center for Education Research.

Conference Board of the Mathematical Sciences. (1983a). The mathematical sciences curriculum K-12: What is still fundamental and what is not. Washington, DC: National Science Foundation.

Conference Board of the Mathematical Sciences. (1983b). New goals for mathematical sciences education. Report of a conference sponsored by The Conference Board of the Mathematical Sciences, Airlie House, Warrenton, Virginia, November 13-15, 1983. Washington, DC: Author.

Dalin, P. (1978). Limits to educational change. New York: St. Martin's Press.

Davis, P. J., \& Hersh, R. (1981). The mathematical experience. Boston: Houghton Mifflin.

Freudenthal, H. (1983). Major problems of mathematics education. In M. Zweng, T. Green, H. Pollak, \& M. Suydam (Eds.), Proceedings of the Fourth International Congress on Mathematical Education (pp. 1-7). Boston: Birkhauser. 
Howe, J. (1987). Arithmetic and mathematical concepts. In Centre for Educational Research and Innovation (CERI), Information technologies and basic learning. Paris: Organization for Economic Co-operation and Development.

Kirsch, I. S., \& Jungeblut, A. (1986). Literacy: Profiles of America's young adults (Report No. 16-PL-02). Princeton, NJ: Educational Testing Service, National Assessment of Educational Progress.

Kirsner, S. (1988). Further thought on computation/problem solving debate. (Únpublished manuscript)

McKnight, C. C., Crosswhite, F. J., Dossey, J. A., Kifer, E., Swafford, J. O., Travers, K. J., \& Cooney, T. J. (1987). The underachieving curriculum: Assessing U.S. school mathematics from an international perspective. Champaign, IL: Stipes.

Naisbitt, J. (1982). Megatrends: Ten new directions transforming our lives. New York: Warner Books.

National Coalition of Advocates for Students. (1985). Barriers to excellence: Our children at risk. Washington, DC: Author.

National Commission on Excellence in Education. (1983). A nation at risk: The imperative for educational reform. Washington, DC: U.S. Government Printing Office.

National Council of Teachers of Mathematics. (1987). Curriculum and evaluation standards (working draft). Reston, VA: Author.

National Science Board Commission on Precollege Education in Mathematics, Science, and Technology. (1983). Educating Americans for the 2lst century: A plan of action for improving the mathematics, science, and technology education for all American elementary and secondary students so that their achievement is the best in the world by 1995. Washington, DC: National Science Foundation.

National Science Foundation. (1982). Science indicators, 1982. Washington, DC: U.S. Government Printing Office.

Peddiwell, J. A. (pseudonym). (1939). The saber-tooth curriculum. New York: McGraw Hill.

Pollak, H. (1987, May). Notes from a talk given at the MSEB Frameworks Conference, Minneapolis.

Resnick, L. B. (1987). Education and learning to think. Washington, DC: National Academy Press.

Resnick, D. P., \& Resnick, L. B. (1977). The nature of literacy: An historical exploration. Harvard Educational Review, 47, 370-385. 
Rice, J. M. (1913). Scientific management in education. New York: Hinds, Noble, and Eldredge.

Romberg, T. A. (1984). School mathematics: Options for the 1990s (Chairman's report of a conference). Washington, DC: U.S. Government Printing Office.

Romberg, T. A. (1983). A common curriculum for mathematics. In G. D. Fenstermacher \& J. J. Goodlad (Eds.), Individual differences and the common curriculum: Eighty-second yearbook of the National Society for the Study of Education, Part I (pp. 121-159). Chicago: University of Chicago Press.

Romberg, T. A., \& Carpenter, T. P. (1986). Research on teaching and learning mathematics: Two disciplines of scientific inquiry. In M. C. Wittrock (Ed.), Handbook of research on teaching: A project of the American Educational Research Association (3rd ed., pp. 850-873). New York: Macmillan.

Romberg, T. A., \& Price, G. G. (1983). Curriculum implementation and staff development as cultural change. In G. A. Griffin (Ed.), Staff development: Eighty-second yearbook of the National Society for the Study of Education, Part II (pp. 154-184). Chicago: University of Chicago Press.

Schoenfeld, A. H., \& Herrmann, D. J. (1982). Problem perception and knowledge structure in expert and novice mathematical problem solvers. Journal of Experimental Psychology: Learning. Memory, and Cognition, $\underline{8}, 484-494$.

Shane, H. I., \& Tabler, M. B. (1981). Educating for a new millennium: Views of 132 international scholars. Bloomington, IN: Phi Delta Kappa Educational Foundation.

Stanic, G. M. A. (1984). Why teach mathematics? A historical study of the justification question (Doctoral dissertation, University of WisconsinMadison, 1983). Dissertation Abstracts International, 44, 2347A.

Toffler, A. (1985). The adaptive corporation. New York: McGraw-Hill.

Tyler, R. W. (1931). A generalized technique for constructing achievement tests. Educational Research Bulletin, 8 , 199-208.

Venezky, R. L., Kaestle, C. F., \& Sum, A. M. (1987). The subtle danger: Reflections on the literacy abilities of America's young adults (Report No. 16-CAEP-01). Princeton, NJ: Center for the Assessment of Educational Progress, Educational Testing Service.

Weinzweig, A. I., \& Wilson, J. W. (1977, January). Second IEA mathematics study: Suggested tables of specifications for the IEA mathematics tests. Working Paper I. Wellington, New Zealand: IEA International Mathematics Committee.

Yevennes, M. (1985). The world political economy and the future of the U.S. labor market. World Futures, 21, 147-157. 